\title{
Assessing the Efficiency of Grey-Water Reuse at Household Level and Its Suitability for Sustainable Rural and Human Development
}

\author{
Mohammed Boufaroua $^{1^{*}}$, Abeer Albalawneh $^{2}$ and Theib Oweis ${ }^{1}$ \\ ${ }^{1}$ International Centre for Agricultural Research in the Dry Areas (ICARDA) ICARDA, P.O. \\ Box 950764, Amman 11195, Jordan. \\ ${ }^{2}$ National Centre for Agricultural Research and Extension (NCARE) P.O. Box 639, Baqa'a, \\ Amman, 19381 Jordan.
}

Authors' contributions

This work has been done in a collaboration program between the International Centre for Agricultural Research in the Dry Areas (ICARDA) and the National Centre for Agricultural Research and Extension in Jordan (NCARE) scientists. Authors MB and AA designed the study, performed the statistical analysis, wrote the protocol, and wrote the first draft of the manuscript. Sample collection and analysis were performed by author AA. The project was coordinated by authors $M B$ and $A A$ and directed by author TO. All authors read and approved the final manuscript.

Case Study

Received $8^{\text {th }}$ March 2013

Accepted $6^{\text {th }}$ June 2013

Published $4^{\text {th }}$ July 2013

\section{ABSTRACT}

In arid and semi-arid regions where water is in short supply, grey-water treatment offers the possibility of supplemental water resources for reuse in irrigation at household and farm levels. The gravest environmental challenge that Jordan faces today is water scarcity. Jordan has one of the lowest per capita levels of water resources in the world. Regions with fewer than $1000 \mathrm{~m} 3$ per person per year are defined as water-scarce. Water-scarcity hinders economic development, strains the environment, and drastically limits food availability [1]. - In Jordan in 1996; per capita share of water was < $175 \mathrm{~m} 3$ for all uses. The country's population increase, and the periodic massive influxes of refugees from neighboring countries, has created an increasing demand. New unconventional water resources are needed to counteract the negative water balance between supply and demand. Responding to this challenge, grey-water management in the rural and periurban communities of Jordan has been adopted as a solution in collaboration between 
the International Centre for Agricultural Research in the Dry Areas and the National Centre for Agricultural Research and Extension. The project adopted participatory approach with all stakeholders to achieve project's objectives. Several meetings were held with community members and Community Based Organizations in the project area. Furthermore, community involvement and gender consideration are important factors to achieve sustainability in project implementation. The general goal of the project is to improve the quality of life and well-being for rural Jordanians through adopting appropriate grey-water treatment units for the purpose of crop production and income generation. A monitoring program was implemented in August 2010 in six locations. Of these locations, three used volcanic tuff material as the filtration media and the others used white gravel. The monitoring program included collection of water, soil and plant samples. The water sample analyses showed that using medium-sized volcanic tuff as a filtration media is more effective than using medium-sized gravel. There was a $73 \%$ reduction in the biological oxygen demand when using volcanic tuff and a $49 \%$ reduction when using gravel. Moreover, grey-water quality after treatment was within the permissible limits of the Jordanian standards for its use in irrigation. The results of plant leave quality and soil analysis being irrigated with grey-water showed that grey-water has no adverse effects on plant quality and soil properties. However, leaching of soil with fresh water from time to time is recommended. Furthermore, community involvement and gender consideration are important factors to achieve sustainability in project implementation.

Keywords: Grey-water; community participation; constructed wetland; quality.

\section{INTRODUCTION}

The most severe water scarcity in the world is in the Middle East, and critical water shortages in the Eastern Mediterranean region as a whole affect the region's social and economic potential, increase the land vulnerability to salinization and desertification and raise the risk of political conflict around this limited resource [2]. According to Allan [3], the region "ran out of water in the 70s" and is currently surviving on virtual water and in cases on over-exploiting its own renewable water resources.

Jordan is one of the most water-deprived countries in the world. The number of countries or territories with less than $1000 \mathrm{~m} 3 /$ inhabitant is 29. The ten poorest countries in terms of water resources per inhabitant are Bahrain, Jordan, Kuwait, Libya, Maldives, Malta, Qatar, Saudi Arabia, United Arab Emirates and Yemen [4].

Daily per capita water consumption rate is quite low in Jordan, and the cost of supplying water continues to rise. This extreme water scarcity and increasing cost of supply is a very serious constraint to Jordan's economic growth. The renewable internal freshwater resources per capita in Jordan was $115.30 \mathrm{~m} 3$ in 2009, according to a World Bank report, published in 2010, while the point of concern for water scarcity is estimated at $500 \mathrm{~m} 3 \mathrm{per}$ capita per year [1].

Grey-water can be considered as a good alternative providing non-potable water for household usage, and thus reducing per capita water use by 50\% [5].For this reason it is an attractive and sustainable low cost water source especially in arid and semi-arid areas, such as Jordan, due to water scarcity and fluctuation in rainfall patterns [6]. 
Madaba, the site of our project, is located at $30 \mathrm{KM}$ the south-west of the capital Amman. It covers the area of $939 \mathrm{Km} 2$ and accommodates 130000 population, of which $42 \%$ lives in rural areas [7]. People of Madaba suffer from a chronic water shortage encountering severe water problems. The people of Madaba depend on "Al-Heidan" wells, where the full capacity of wells ( $800 \mathrm{~m} 3$ / hour) is not enough to cover the actual demand of people. According to Madaba water directorate, additional $400 \mathrm{~m} 3$ is required to be pumped per hour as a complementary to cover the shortage in water supply.

On the other hand, most of Madaba's villages (rural settings) are not served with centralized sewerage systems. Individual household cesspits and wastewater discharge into open environments are the solely options for wastewater management, which likely to contribute in high contamination of groundwater with coliform bacteria, nitrates and heavy metals.

The quality of grey-water varies depending on the volume of supply water consumed per person in a household, the initial quality of the water supply, the source of the grey-water, and on chemicals used in the washing/bathing process. The volume of water supply consumed by a household depends on the scarcity, costs of water supply and on the water conservation measures being taken within the household. The health risk associated with grey-water is related to the microbial quality of grey-water at the point of irrigation, on how irrigation is carried out, and the type of crops being irrigated [8]. The use of grey-water as an alternative irrigation source in Jordan is considered an effective method for saving fresh water and increasing green areas [9].

This paper presents the results of using an integrated approach to manage grey-water at the household level in Jordan. The main project community (benchmark) site was in Madaba Governorate, Jordan, where the households were not connected to a sewer system. In the absence of a sewer system, the households spend a considerable amount of time and effort in collecting and disposing of domestic wastewater. The treated grey-water is used for irrigation at household level. Grey-water that is recycled from household washing can be used to irrigate home gardens, according to a new study by Jordanian researchers. The researchers found that treatment units supplied by the Jordanian government produced small quantities of recycled water that could be used to irrigate gardens, whilst meeting national standards for irrigation of trees and many home-grown crops [10].

With the goal of better livelihoods through efficient and sustainable use of available water resources in dry areas, the project aims to address improvement in grey-water quality and community-based interventions leading to safe and productive use of grey-water for crop production systems at the household level. Moreover, the project aims at implementing, with the participation of households, grey-water collection, treatment, and productive reuse in home farming to improve the income of households.

\section{MATERIALS AND METHODS}

\subsection{Site Selection}

Using a participatory process, by involving the farming communities, local leaders and NGOs, and from field visits undertaken, Al-Faisalia, Al-Areash and Jraineh villages were selected within the Madaba Governorate as the main project implementation sites. The individual households were selected on their residential location, their social setting and their economic level taking into consideration all the available criteria which have been discussed 
by the different partners. Several indicators were prioritized (multi-criteria approach) and the selection was based on the selected project sites facing a shortage of freshwater resources for different uses - average annual rainfall of $<200 \mathrm{~mm}$ - and the limited agriculture-related activities in summer because of this lack of water for irrigation.

The selection of the pilot sites was according to different indicators established in a multicriteria participatory approach:

- Presence of a home garden to be able to use the treated grey water for irrigation;

- Family size, i.e. number of family members to provide enough water to be treated;

- Rate of water consumption per household to ensure enough water for the treatment units;

- Willingness of the household to cooperate in implementing grey-water collection, treatment and use for irrigation of the home garden or olive trees;

- Ability of the household to contribute to the construction of the grey-water collection and treatment system to follow the monitoring activities with scientists to participate in the success of the project;

- Cropping pattern to be irrigated by the small quantities of recycled water.

An initial assessment study for each household was conducted in order to facilitate the selection process. In Al-Faisalia, Al-Areash and Jraineh villages, 98 houses were considered for project implementation.

The project conducted several initial meetings in the project area, to increase knowledge and understanding about grey-water as an alternative source of irrigation water. Then benchmark site and households were selected and characterized.13 grey-water treatment units were installed according to the design of International Centre for Agricultural Research in the Dry Areas (Fig. 1) at Al-Faisalia, Al-Areash and Jraineh villages of Madaba Governorate (the project target area). The selected households and sites were then characterized.

Greywater is collected in $100 \mathrm{~L}$ Polyethylene barrel. Electrical aerator is installed in this barrel to provide oxygen for aerobic treatment. The duration of aeration is estimated at 5 hours, and then the overflowed water moves toward wetland. The dimensions of wetland in all units were $4 \mathrm{~m}$ length, I $\mathrm{m}$ with and $0.8 \mathrm{~m}$ depth.

\section{Grey Water Treatment Unit}

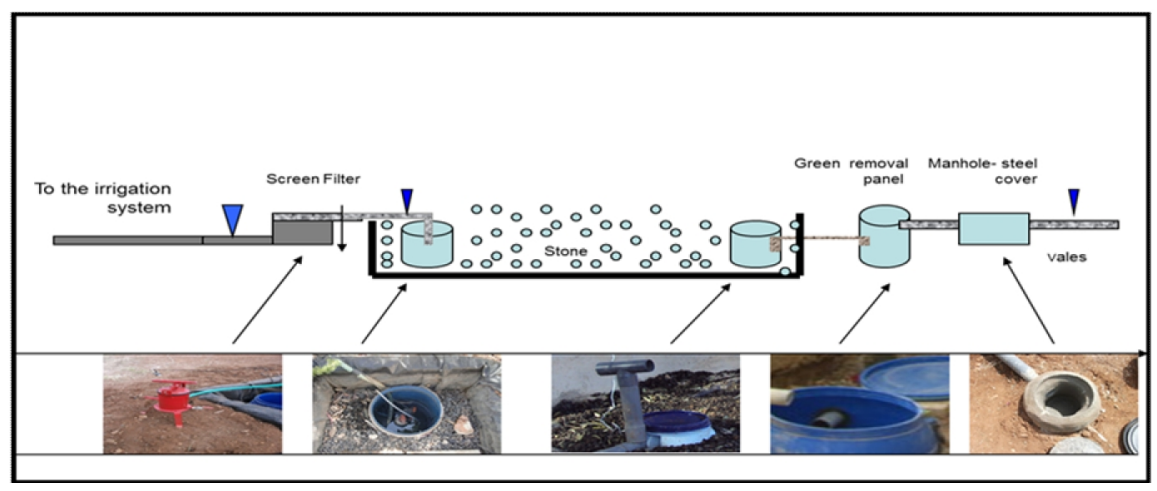

Fig. 1. Design of the grey water treatment unit [11] 


\subsection{Participatory Approach}

The project beneficiaries started their own grey-water reuse association. This society was considered a byproduct of the project and the beneficiaries were very enthusiastic to succeed in their tasks.

The training programs for the beneficiaries' households' wives was used as a tool to make group discussions more effective and participants are more deeply involved in the group process, in considering all opinions, and in working towards jointly supported results. The project created an initiative method in transferring the knowledge at community level through local beneficiaries' women community (LBWC).

The selected women for LBWC were characterized by the following factors: (1) one of the project participants; (2) participated in all training activities undertaken by the project; (3) active and having initiative motivation; (4) good communication skills; (5) head or membership of one social society; and (6) practical experience in grey-water treatment unit management.

The mandates of LBWC are the following: (1) start local women networking; (2) train other women (women-to-women learning method); (3) help the project to achieve the 'on-site training of the households for grey-water use best practices; (4) work as a member of the project team and under the project coordination; and (5) introduce the grey-water concepts to within and outside the community.

As a result, LBWC has undertaken 28 training sessions with the beneficiaries' households' wives. The training topics in these sessions were: (1) Inside home practices that provide good quality and quantity of grey-water; (2) natural alternatives as a substitute of using chemical detergents; (3) home industry of natural detergents; (4) treatment unit's cleaning procedure; (5) health and safety measures while using grey-water as an irrigation source; and (6) best crop patterns for grey-water irrigation that increase the family income.

\subsection{Follow-Up and Monitoring Plan}

A monitoring program began in August 2010 until March 2012 for six locations (three of them using the tuff material as filtration media and the others using white gravels as filtration media). The monitoring program includes the collection of water, soil and plant samples. A comprehensive program for networking, awareness and dissemination was implemented for these six sites selected according to the criteria mentioned above.

Grey-water quality depends mainly on the water source, plumbing system, living habits, and personal hygiene of the users. Other factors such as cleaning products used, dishwashing patterns, laundering practices, bathing habits and disposal of household chemicals will influence the characteristics of water. As a result, the physical, chemical, and biological characteristics of grey-water vary greatly. Hence, it may cause health risks and affect the surrounding environment. Therefore, the selection of Grey-water treatment methods should be based on the specific characteristics of water [12].

In this paper an evaluation of a small scale project which was conducted in Jordan during the period 2010-2012 is presented; this project represents a simple way for collecting and reusing grey-water to irrigate trees, and green areas. 
Two types of filtering media were used to fill the wetland bed; volcanic tuff and white gravel (both with effective size 1-3 cm). The treated grey-water was being reused for olive and fruit trees irrigation.

\section{DATA COLLECTED}

A program of periodic visits to the project sites was prepared along with a checklist of tasks to be undertaken during the visits. These tasks included any necessary water, soil and plant sampling; testing of the system's operation; meeting with the households; discussing issues related to grey-water and obtaining feedback.

The objective was to monitor and compare the quality of the treated and untreated greywater. In addition, the site monitoring plan assessed the chemical and biological changes in the soil and in plant parameters after using treated grey-water for irrigation.

The monitoring process lasted 16 months for 6 constructed units, during which 75 samples from water, soil and plant were taken periodically. Table (1) shows information for selected households.

Table 1. General information for each beneficiary selected for monitoring and evaluation

\begin{tabular}{|c|c|c|c|c|c|}
\hline Benefi-ciary & $\begin{array}{l}\text { No. of } \\
\text { household } \\
\text { members }\end{array}$ & $\begin{array}{l}\text { No. of sinks } \\
\text { and showers }\end{array}$ & $\begin{array}{l}\text { Average of water } \\
\text { consumption/ } \\
\text { week } \mathrm{m}^{3}\end{array}$ & $\begin{array}{l}\text { Area of } \\
\text { house } \\
\mathrm{m}^{2}\end{array}$ & $\begin{array}{l}\text { Area of } \\
\text { home } \\
\text { garden } \mathrm{m}^{2}\end{array}$ \\
\hline 1 & 6 & 3 sinks & 5 & 170 & 3750 \\
\hline 2 & 6 & 5 sinks & 4 & 150 & 750 \\
\hline 3 & 4 & 7 sinks & 3 & 150 & 300 \\
\hline 4 & 7 & $\begin{array}{l}4 \text { sinks \& } \\
\text { shower }\end{array}$ & 4 & 210 & 1500 \\
\hline 5 & 10 & $\begin{array}{l}\text { sinks \& } 1 \\
\text { shower }\end{array}$ & 4 & 120 & 500 \\
\hline 6 & 8 & 3 sinks & 4 & 160 & 500 \\
\hline
\end{tabular}

\section{RESULTS AND DISCUSSION}

\subsection{Water Quality}

In order to evaluate the performance of constructed units in grey-water treatment, 18 random samples were taken from raw and treated grey-water. Filtering media was considered in sampling process. Table (2) shows the grey-water quality before and after treatment for both treatment media.

The analysis of the water samples showed that using both volcanic tuff and gravel as the treatment media was effective. The quality of the grey-water after treatment was within the permissible limits of the Jordanian standard for using grey-water for irrigation (Table 2).

However, volcanic tuff was more effective as a treatment media than gravel. Elsewhere in Jordan, a septic tank followed by an intermittent sand filter was piloted in the northern- 
eastern Badia to deal with grey-water generated from one household. A $1 \mathrm{~m} 3$ septic tank followed by $6 \mathrm{~m} 2$ intermittent sand filter of $1 \mathrm{~m}$ in depth were used to treat an average flow of 150L/Day of grey-water effluent from single household in Abu Al Farth Village in the Badia of Jordan. Efficiency of OM removal (five-day Biological Oxygen Demand represented by BOD5) and the Total Suspended Solids (TSS) were 87 and $85 \%$, respectively [13]. In the present study, the reduction in BOD5 was 73 and $49 \%$ when using volcanic tuff and gravel, respectively; TSS decreases in both treatments to reach approximately the Jordanian standards (Table 2).

The reduction in the fecal coliforms (FC) count using white gravel (-99\%) was much higher than that for volcanic tuff $(-15,7 \%)$. Initially FC counts recorded in grey-water in volcanic truff units had much higher values than those in white gravels because of the sources of water coming from the different cleaning operations. Grey-water from bathing recorded the lowest mean, while that from the kitchen had the highest mean colony count and are more present in the volcanic tuff units. We can explain this difference in fecal coliform results after treatment by the fact that it was easier to treat FC counts present in white gravel units. Results also showed that disinfection unit is required when using constructed units in order to get rid of high account of fecal coliforms. The EC of the grey-water increased from 1.28 to $1.49 \mathrm{dS} / \mathrm{m}$ for volcanic tuff as the treatment media, and increased slightly from 1.50 to 1.54 $\mathrm{dS} / \mathrm{m}$ for gravel (Table 1).

Table 2. Quality of grey-water after using two different treatment media and comparison of the treated grey-water quality with Jordanian standards for grey-water for irrigation

\begin{tabular}{llllll}
\hline $\begin{array}{l}\text { Treatment } \\
\text { material }\end{array}$ & Parameters & $\begin{array}{l}\text { Pre- } \\
\text { treatment1 }\end{array}$ & $\begin{array}{l}\text { Post- } \\
\text { treatment2 }\end{array}$ & $\begin{array}{l}\text { Variation } \\
\text { (\%)3 }\end{array}$ & $\begin{array}{l}\text { Jordanian } \\
\text { standard }\end{array}$ \\
\hline Volcanic & BOD5 $(\mathrm{mg} / \mathrm{L})$ & 444 & 121 & -73 & 300 \\
tuff & $\mathrm{COD}(\mathrm{mg} / \mathrm{L})$ & 860 & 301 & -65 & 500 \\
& $\mathrm{pH}$ & 6.2 & 6.7 & +8 & $6-9$ \\
& $\mathrm{EC}(\mathrm{dS} / \mathrm{m})$ & 1.28 & 1.49 & +16 & - \\
& $\mathrm{Cd}(\mathrm{ppm})$ & 0.002 & 0.002 & unchanged & 0.01 \\
& $\mathrm{~Pb}(\mathrm{ppm})$ & 0.01 & 0.01 & unchanged & 0.1 \\
& $\mathrm{FC}(\mathrm{coliform} / 100 \mathrm{~mL})$ & 784,163 & 661,259 & $-15,67$ & Unlimited \\
Gravel & $\mathrm{TSS}$ & 1245 & 193 & +84 & 200 \\
& $\mathrm{BOD}(\mathrm{mg} / \mathrm{L})$ & 407 & 209 & -49 & 300 \\
& $\mathrm{COD}(\mathrm{mg} / \mathrm{L})$ & 731 & 354 & -52 & 500 \\
& $\mathrm{pH}$ & 6.9 & 6.8 & +1 & $6-9$ \\
& $\mathrm{EC}(\mathrm{dS} / \mathrm{m})$ & 1.50 & 1.54 & +3 & - \\
& $\mathrm{Cd}(\mathrm{ppm})$ & 0.002 & 0.002 & unchanged & 0.01 \\
& $\mathrm{~Pb}(\mathrm{ppm})$ & 0.01 & 0.01 & unchanged & 0.1 \\
& $\mathrm{FC}(\mathrm{coliform} / 100$ & 452,844 & 4,657 & -99 & Unlimited \\
& $\mathrm{mL})$ & & & & \\
& $\mathrm{TSS}$ & 939 & 209 & +78 & 200 \\
\hline
\end{tabular}

The $\mathrm{Na}$ concentration and sodium absorption ratio (SAR) both decreased under the treatment using the white gravel media; however, both parameters increased slightly when using the volcanic tuff. The increases or decreases in $\mathrm{Na}$ content did not affect $\mathrm{pH}$ of the treated water, which remained acidic. The concentrations of the other cations and anions generally increased for both media, mainly because of evaporation losses from the treatment bed. 
Finally, there were no problems with $\mathrm{Pb}$ and $\mathrm{Cd}$ as their concentrations remained constant and were not affected by either treatment media.

As shown in Table (2), both media produced acceptable grey-water quality for the purpose of fruit trees irrigation and will not have bad influence plant growth. However, using volcanic tuff in constructed wetland might be considered better option comparing to the traditional gravel. Results also showed that disinfection unit is required when using constructed wetland in order to get rid of high account of fecal coliforms.

\subsection{Soil Characteristics}

The impact of grey-water reuse on soil characteristics was examined using soil samples taken before and after two years of grey-water application (Table 3).

Table 3. Soil properties before and after using grey-water for two years

\begin{tabular}{|c|c|c|c|}
\hline Parameters & Unit & Before & After \\
\hline NO3-N & $\%$ & 93 & 51 \\
\hline $\mathrm{K}$ & ppm & 969 & 670 \\
\hline $\mathrm{Cd}$ & $\mathrm{ppm}$ & 0.35 & 0.18 \\
\hline $\mathrm{Pb}$ & $\mathrm{ppm}$ & 1.5 & 0.94 \\
\hline $\mathrm{Zn}$ & ppm & 16 & 18 \\
\hline $\mathrm{P}$ & ppm & 47 & 28 \\
\hline OM & $\%$ & 2.9 & 2.8 \\
\hline $\mathrm{pH}$ & & 7.6 & 7.8 \\
\hline $\mathrm{Mg}$ & $\mathrm{meq} / \mathrm{L}$ & 5.4 & 1.7 \\
\hline $\mathrm{Ca}$ & $\mathrm{meq} / \mathrm{L}$ & 6.5 & 2.0 \\
\hline $\mathrm{Na}$ & $\mathrm{meq} / \mathrm{L}$ & 2.1 & 1.2 \\
\hline $\mathrm{Cl}$ & $\mathrm{meq} / \mathrm{L}$ & 2.8 & 1.3 \\
\hline $\mathrm{Na}$ & $\%$ & 17.5 & 24.0 \\
\hline SAR & & 0.91 & 0.87 \\
\hline Salinity EC & $\mathrm{dS} / \mathrm{m}$ & 1.26 & 0.44 \\
\hline
\end{tabular}

Using grey-water for irrigation had no negative impacts on soil properties. The soil at all depths for the intervals sampled and at all the monitored locations showed a low salinity level within the range of $0.263-0.627 \mathrm{dS} / \mathrm{m}$ and average $0.44 \mathrm{dS} / \mathrm{m}$ (Table 3). However, the drop in soil salinity was not a result of using grey-water for irrigation, but was due to natural salt leaching during a recent rainy season. There was a relatively high rainfall and the irrigation was continuous regardless of a rain event or wet soil conditions. This situation enhanced leaching of the soil salinity in all six monitored locations.

Chemical analyses of the soil clearly showed that using grey-water, treated either using volcanic tuff or white gravel, reduced the concentrations of NO3-N, K, Cd, Pb, P, Mg, Ca, Na and $\mathrm{Cl}$. However, the $\mathrm{Na}$ concentration increased in soil irrigated with grey-water treated with volcanic tuff, without affecting the SAR, but slightly raised the soil $\mathrm{pH}$. The main reason for this rise in soil pH was probably the leaching of soil salinity (Table 3 ).

The $\mathrm{Zn}$ concentration was an exception. Its concentration in soil increased regardless of the treatment media used. However, as the quality of grey-water is variable with time, the important issue is to check for any alarming change in the soil quality that will affect the 
plant. It is expected that nutrients diminution ( $\mathrm{N}$ and $\mathrm{P}$ ) could lead to an impoverishment of the soil and a special concern should be given for this issue.

The results showed that using grey-water for irrigation does not have negative impacts on soil properties, albeit with some increase in Na concentration.

\subsection{Quality of Olive Leaves}

More than the positive growth of the olive trees observed by the farmers, chemical and biological analyses of the leaves of olive trees irrigated with treated grey-water in the locations of our network of treatment units were performed at two different times: the first before using grey-water and the second after two years of using treated grey-water for irrigation. The Tables 4 and 5 below show the biological and chemical analysis of leaves. Table 4 indicates a trend of no change in the presence of fecal coliforms on the plants, with the exception of locations 3 and 5 . Fecal coliforms increased at location 3 , while at location 5 fecal coliforms decreased on the plant.

Table 4. Biological analysis of plant leaves before starting the use of treated greywater, and after 2-years of its use for irrigation at different locations

\begin{tabular}{lll}
\hline Location no. & Before & After \\
\hline 1 & FC (coliform/gm) & FC (coliform/gm) \\
3 & 3 & 3 \\
4 & 3 & 400 \\
5 & 3 & 3 \\
6 & 900 & 400 \\
\hline
\end{tabular}

The chemical analysis of the leaves (Table 5) showed clearly that the concentrations of $P, K$ and $\mathrm{Zn}$ had decreased; while $\mathrm{N}, \mathrm{Pb}$ and $\mathrm{Cd}$ concentrations increased. The high $\mathrm{N}$ values were because leaves were the plant parts analyzed; the values for $K$ and $P$ were determined from leaves collected at two different times of the year. Samples before and after the greywater use were taken from trees during December and March, respectively. The difference in the sampling times makes it difficult to conclude regarding the decreases in $\mathrm{K}$ and $\mathrm{P}$ concentrations. Both $\mathrm{Pb}$ and $\mathrm{Cd}$ concentrations increased while their concentrations in the grey-water had not changed, indicating that another source for these metals was responsible for their increased concentrations in leaves.

Table 5. Chemical analyses of olive tree leaves before and after using treated greywater for irrigation for two years

\begin{tabular}{llllllllllll}
\hline Before & After & Before & After & Before & After & Before & After & Before & After & Before & After \\
\hline $\mathbf{N ~ ( \% )}$ & & $\mathbf{P ~ ( \% )}$ & & $\mathbf{K ~ ( \% )}$ & \multicolumn{3}{c}{$\mathbf{P b}(\mathbf{p p m})$} & $\mathbf{C d}(\mathbf{p p m})$ & $\mathbf{Z n}(\mathbf{p p m})$ \\
\hline 1.54 & 1.79 & 0.13 & 0.10 & 0.80 & 0.43 & 3.21 & 8.69 & 0.46 & 0.95 & 18.15 & 7.56 \\
\hline
\end{tabular}

The grey-water did not have any adverse impacts on plant quality (Table 3 ). However, further investigation is required to explain the variations in $\mathrm{Pb}$ and $\mathrm{Zn}$ concentrations. Several studies have been conducted to identify the sources and removal efficiencies of metals in grey-water. Eriksson et al. [14] investigated the sources, presence and potential fate of $\mathrm{Cd}, \mathrm{Pb}$, mercury $(\mathrm{Hg})$ and nickel $(\mathrm{Ni})$ in the grey-water treatment systems. Their study showed that onsite treatment could remove a third to a half of $\mathrm{Pb}, \mathrm{Hg}$ and $\mathrm{Ni}$ but showed no 
significant removal of $\mathrm{Cd}$. Based on geochemical modeling, they concluded that metals should not pose a problem for reuse in toilet flushing and fruit tree irrigation; however, potential health problems were associated with sludge disposal [10]. Results of the present study (Table 3) are also consistent with the findings of a study of the benefits and risks associated with domestic grey-water reuse for the purposes of vegetable garden irrigation, in which heavy metals were within the acceptable ranges in both grey-water and plant leaves [15].

\section{CONCLUSIONS}

The treatment units implemented at the household level in Madaba Governorate in Jordan were evaluated and several important parameters were measured. Overall, the results were satisfactory and were consistent and compatible with Jordanian standards. Interviews with community members and farmers indicated wide community interest in using the treated grey-water, especially after observing the positive growth of the olive trees.

Using treated grey-water from treatment units is a promising strategy for achieving significant local water savings. Research on further economic benefits is underway to determine the real financial returns to farmers and the community as a whole.

The main conclusions from this project were:

$\checkmark \quad$ The composition and characteristics of grey-water varied significantly after being treated by using the tuff material white gravels as filtration media.

$\checkmark$ The quality of the treated grey-water complied with Jordanian standards for reclaimed wastewater reuse in restricted irrigation.

$\checkmark$ Knowledge of local people should be recognized and participatory approaches applied when investigating integrated water resources management programs for small communities. However, intensive awareness campaigns and training sessions are required.

$\checkmark \quad$ Using treatment units for grey-water treatment in rural and peri-urban communities can be a good option with Both media treatments used (i.e. volcanic tuff and white gravel), performed well in producing treated grey-water conforming within Jordanian standards and without adverse effects on soil or plants.

$\checkmark \quad$ Using volcanic tuff as the treatment media was more effective than white gravel in reducing $B O D$ and $C O D$ values.

$\checkmark$ Using volcanic tuff as the treatment media caused a greater increase in water salinity than gravel.

$\checkmark$ Heavy metals were within the acceptable ranges in both grey-water and plant leaves

\section{COMPETING INTERESTS}

Authors have declared that no competing interests exist.

\section{REFERENCES}

1. Population Institute reports: Population and water; 2010.

2. Brooks DB, Mehmet O. Water Balances in the Eastern Mediterranean. Ed. Ottawa Canada: International Development Research Centre (IDRC); 2000. 
3. Allan JA. The Middle East water question: looking behind conventional assumptions. Journal of Social Affairs. Journal of the Sociological Association of the UAE and the University of Sharjah. 2002;19:37-52.

4. Food and Agriculture Organization of the United Nations (F.A.O). Water reports: Review of world water resources by country. Ed. ISSN. 2003;1020-1203.

5. Oschmann N, Nghiem LD, Scafer A. Fouling mechanisms of submerged ultra-filtration membranes in greywater recycling. Desalination journal. 2005;179:215-223.

6. Al-Jayyousi OR. Greywater reuse: towards sustainable water management. Desalinisation. 2003;156:181-192.

7. Department of statistics in Jordan. Results of the population and housing census: economic characteristics; 2004.

8. Engelbrecht JF, Murphy KO. What stops me from using grey water. CSIR; 2006.

9. Pinto U, Maheshshwari BL, Grewal HS. Effects of grey-water irrigation on plant growth, water use and soil properties. Resour Conserv Recy. 2010;54:429-435.

10. Finley S, Barrington S, Lyew D. Reuse of domestic grey-water for the irrigation of food crops. Water Air Soil Pollut. 2009;199:235-245.

11. Boufaroua M, Al Balawneh A. Final report of the project "Community-based Interventions for Productive Use of Grey-water in Home Farming"; 2012.

12. Aljaradin M, Aboulila TS. Evaluation of using grey-water as an alternative irrigation source in Jordan. Journal of Water Management and Research (Vatten). 2011;67(2):119-122.

13. Assayed A, Dalahemeh S, Suleiman W. Onsite greywater treatment using septic tank followed by intermittent sand filter: a case study of Abu Al Farth village in Jordan. International Journal of Chemical and Environmental Engineering (IJCEE). 2010;20780737(1):72-77.

14. Eriksson E, Andersen H, Madsen T, Ledin A. Greywater pollution variability and loadings. Ecological Engineering. 2009;35:661-669.

15. Al-Hamaideh $\mathrm{H}$, Bino $\mathrm{M}$. Effect of treated grey-water reuse in irrigation on soil and plants. Desalination journal. 2010;256:115-119.

(c) 2013 Boufaroua et al.; This is an Open Access article distributed under the terms of the Creative Commons Attribution License (http://creativecommons.org/licenses/by/3.0), which permits unrestricted use, distribution, and reproduction in any medium, provided the original work is properly cited.

\section{Peer-review history:}

The peer review history for this paper can be accessed here: http://www.sciencedomain.org/review-history. php?iid=226\&id=5\&aid=1609 